Wireless Networks 12, 137, 2006 (c) 2006 Springer Science + Business Media, Inc. Manufactured in The Netherlands.

\title{
Erratum
}

The publisher regrets that the order of authors published incorrectly in Wireless Networks 11:4 July 2005, pp. 363-382. The correct order of authors and affiliations appears below:

\section{A Receiver-Centric Transport Protocol for Mobile Hosts with Heterogeneous Wireless Interfaces}

\section{HUNG-YUN HSIEH}

Department of Electrical Engineering, Graduate Institute of Communication and Engineering, National Taiwan University, Taipei, Taiwan, R.O.C.

KYU-HAN KIM, YUJIE ZHU and RAGHUPATHY SIVAKUMAR

School of Electrical and Computer Engineering, Georgia Institute of Technology, Atlanta, GA 30332, USA 